\title{
Lion man takes pride of place as oldest statue
}

\section{Rex Dalton, Reno}

Intricate ivory carvings said to be the oldest known examples of figurative art have been uncovered in a cave in southwestern Germany. Researchers say that the finding could change our understanding of early man's imaginative endeavours.

The artefacts - including a figurine depicting a Lowenmensch ('lion man') - have been carbon-dated to around 30,000 years ago, when some of the earliest known relatives of modern humans populated Europe.

Discovered last year by a team led by US archaeologist Nicholas Conard of the University of Tübingen in Germany, at the Hohle Fels cave near Ulm, the objects include figures depicting a horse and a bird.

Conard says he thinks that the figures are older than a previously discovered Lowenmensch, fragments of which were found by German archaeologists in 1939 near Vogelherd and dated to about the same time. Until now, those artefacts were accepted as the oldest examples of figurative art in the world. The newly discovered objects are older, Conard argues, as they were uncovered at a lower level in the cave floor's sediments.

"These discoveries have incredible significance," says Clive Gamble, an archaeologist at the University of Southampton, UK. "They depict the animal world in a semi-realistic way. It shows early man moving from his immediate world to an imaginative world."

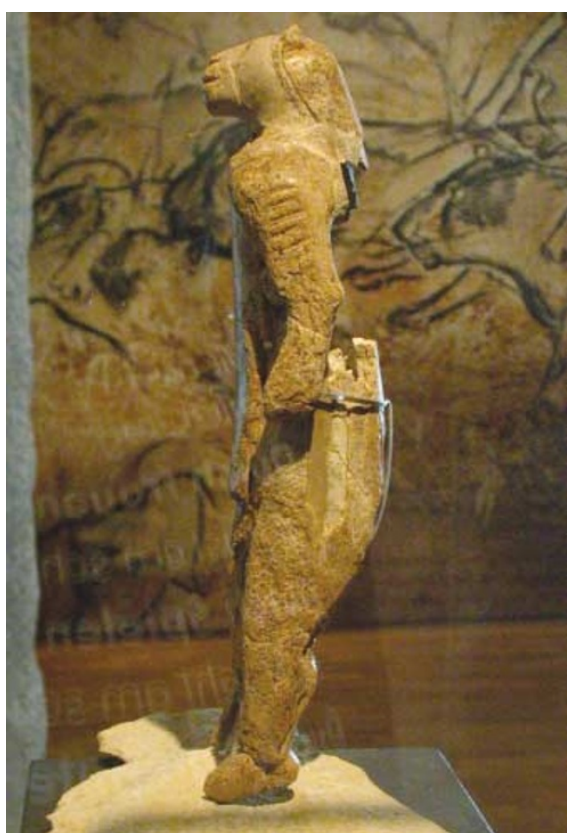

The Vogelherd 'lion man' could lose its crown to another as the oldest figurative work of art.

Conard reported the discovery on 30 July at the Sixteenth Congress of the International Quaternary Association in Reno, Nevada, during a lecture on the human colonization of Europe. He is now preparing a manuscript on the discovery for publication.

Conard, who has studied human migra- tion from Africa at dig sites stretching from Syria to Germany, believes that humans first arrived in central Europe by following the River Danube west into the area. The figurines add a new dimension to theories about the Danube route, agrees Gamble. "During the Ice Age in Europe, the frozen Danube would be like a highway," he says, "providing a fast track to new environments."

Fossil remains suggest that modern humans and Neanderthals both lived in Europe during this period. Conard reported that the sedimentary levels in which the ivory carvings were embedded did not include any Neanderthal fossils. But some archaeologists argue that it is possible that the muchmaligned Neanderthals produced similar objects. "I don't think that is as far-fetched as some people might think," says Jeffrey Brantingham, an archaeologist at the University of California, Los Angeles. "These objects are pushing the markers and traits" of modern man "further back into time", he says.

Archaeologists have pointed out that beads, bone points and pendants have already been discovered in association with Neanderthal fossils. Attributing artefacts to one of the two hominid groups remains difficult, says Brantingham. Gamble says that the discovery will spur fresh exploration of France, Spain and South Africa, where even older cave drawings - but not figurative art of this age - have been identified.

\section{Britain set to pull plug on nuclear-fuel reprocessing}

\section{Quirin Schiermeier}

The United Kingdom looks set to get out of the nuclear-fuel reprocessing business, after a government discussion paper suggested that British Nuclear Fuels (BNFL) shift its emphasis to nuclear decommissioning and waste disposal.

The suggestion has prompted a wave of speculation that BNFL, which runs the Thorp (thermal oxide reprocessing) plant at Sellafield, Cumbria, will close it by 2010 , when its current contracts will have expired.

BNFL officials say that no final decision had been made to close the Thorp plant, which cost $\mathfrak{E} 1.8$ billion (US $\$ 2.8$ billion) to build and only opened in 1994. But David Bonser, the company's deputy chief executive, acknowledges that Thorp has no more orders after 2010. "Beyond the point that current customers have placed orders, every industry has doubts about what its future's going to be, and we're no different," Bosner told the BBC.

BNFL is owned by the UK government, but will be taken over by a new Nuclear
Decommissioning Authority, responsible for cleaning up Britain's nuclear sites, in 2005.

Spent fuel from nuclear power stations is separated at Thorp into uranium, plutonium and highly radioactive fission products. Uranium and plutonium are then recycled for possible re-use as nuclear fuel. The remaining high-level nuclear waste is turned into a radioactive glass and placed in metal canisters for storage.

Thorp will lose much of its workload when a Japanese reprocessing plant opens for business in 2005. If Thorp closes, Japan and France will be the only countries left pursuing a complete nuclear fuel cycle of the sort widely envisaged when civilian nuclear power emerged 50 years ago. The United States abandoned the fuel cycle in the 1970s following criticism that it produced materials suitable for use in nuclear weapons.

Britain had seen nuclear reprocessing as a money-earner, but business has failed to materialize, and Thorp operates at just $50 \%$ of its capacity. "Reprocessing is a profitable business as long as uranium prices are high,"

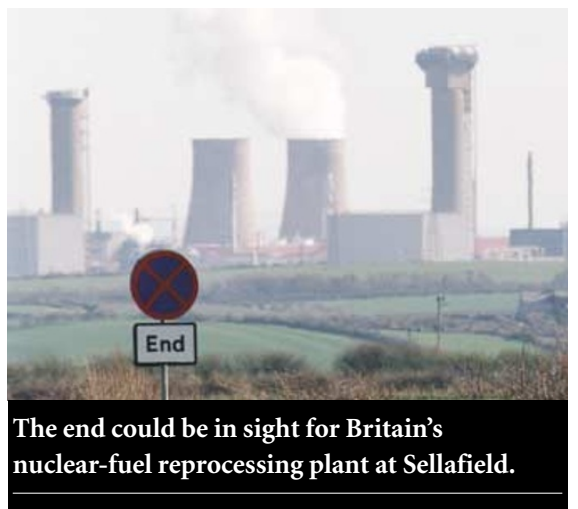

says Ian Hore-Lacy, a spokesman for the World Nuclear Association, a London-based lobby group. "But prices have been low for over a decade because of uranium supplies from Russian weapon stockpiles."

In addition, several European countries are about to ban the export of spent nuclear fuel for reprocessing, points out Heinz Sager, a spokesman for NAGRA, the Swiss National Cooperative for the Disposal of Radioactive Waste. 